University of Nebraska - Lincoln

DigitalCommons@University of Nebraska - Lincoln

Faculty Publications, Department of Psychology

Psychology, Department of

$12-12-2007$

\title{
Infl uence of nicotine on positive affect in anhedonic smokers
}

Jessica Werth Cook

University of Washington and Puget Sound Health Care System, jwcook@ctri.wisc.edu

Bonnie Spring

Northwestern University

Dennis E. McChargue

University of Nebraska-Lincoln, dmcchargue2@unl.edu

Follow this and additional works at: https://digitalcommons.unl.edu/psychfacpub

Part of the Psychiatry and Psychology Commons

Werth Cook, Jessica; Spring, Bonnie; and McChargue, Dennis E., "Infl uence of nicotine on positive affect in anhedonic smokers" (2007). Faculty Publications, Department of Psychology. 277.

https://digitalcommons.unl.edu/psychfacpub/277

This Article is brought to you for free and open access by the Psychology, Department of at DigitalCommons@University of Nebraska - Lincoln. It has been accepted for inclusion in Faculty Publications, Department of Psychology by an authorized administrator of DigitalCommons@University of Nebraska - Lincoln. 
Published in Psychopharmacology 192 (2007), pp. 87-95; doi 10.1007/s00213-006-0688-5 http://www.springerlink.com/content/0033-3158 Copyright (C) 2007 Springer-Verlag. Used by permission.

Submitted September 11, 2006; accepted December 18, 2006; published online February 3, 2007

Supported in part by grants VA Merit Review, NIH HL63307 and HL59348 to Dr. Spring, DA00467 to Dr. McChargue, and DA14144 to Dr. Cook.

ORIGINAL INVESTIGATION

\title{
Influence of nicotine on positive affect in anhedonic smokers
}

\author{
Jessica Werth Cook $^{1}$,*, Bonnie Spring ${ }^{2}$, and Dennis McChargue ${ }^{3}$
}

${ }^{1}$ University of Washington and Puget Sound Health Care System, Mental Health (7West), 1660 S. Columbian Way, Seattle, WA 98108, USA

${ }^{2}$ Northwestern Medical School, Department of Preventative Medicine, Feinberg School of Medicine, Northwestern University, 680 N. Lakeshore Dr., Suite 1102, Chicago, IL 60611, USA

${ }^{3}$ Department of Psychology, University of Nebraska-Lincoln, 238 Burnett Hall, P.O. Box 880308, Lincoln, NE 68588, USA

* Corresponding author — Jessica Werth Cook; email: jesswc@u.washington.edu

\section{Abstract}

Rationale - The possibility that individuals administer nicotine to self-regulate persistent negative affect has received interest as a possible explanation for the high prevalence of affectively vulnerable smokers. Relatively overlooked, however, is the possibility that smokers might also self-administer nicotine to elevate low positive affect.

Objectives - This study examined whether nicotine administration augmented anhedonic smokers' positive affective response to a positive mood induction.

Materials and methods - Fifty regular smokers (50\% female) underwent two positive mood inductions during which they smoked either a nicotinized or denicotinized cigarette in counterbalanced order. Positive affect was assessed before and at two time points after smoking.

Results - Random effects regression showed a significant anhedonia by condition-by-time interaction $[t(181)=-2.01, p=0.04]$, supporting the hypothesis that anhedonia moderated nicotine's effect on changes in positive affect. Simple effect analyses showed a significant condition-by-time interaction among high anhedonic smokers $[t(91)=2.47, p=0.01]$ but not among less anhedonic smokers $[t(91)=0.34, p=0.73]$.

Conclusion-Smoking nicotine vs placebo heightened anhedonic smokers' ability to be induced into a positive mood, whereas nicotine had no effect on more hedonic smokers' positive mood.

Keywords: Positive affect, Negative affect, Anhedonia, Cigarette smoking, Positive mood induction
T he relationship between biopsychosocial vulnerabilities and nicotine dependence has been conceptualized, for the most part, according to a self-medication model (Breslau et al. 1993; Carmody 1992; Hall et al. 1993). The self-medication hypothesis that posits that persistent negative affect is relieved by the pharmacological effects of smoking has received particular interest as an explanation for the high prevalence of depression among smokers (Glassman et al. 1990). Relatively overlooked, however, is the possibility that nicotine regulates deficient positive affect, another affective vulnerability associated with depression. That omission is surprising given that low positive affect (i.e., anhedonia) is an important feature of major depressive disorder (Watson et al. 1988a; Coyne 1994). Thus, deficient positive affect may be an important and overlooked mechanism influencing smoking, particularly for anhedonic individuals who have chronic difficulties experiencing positive affect in response to rewarding events.

Positive affect is defined as the subjective experience of pleasant and energized mood states that reflect feelings such as enthusiasm, excitement, and alertness (Watson and Tellegen 1985). The paucity of research examining whether 
diminished positive affect contributes to smoking behaviors may reflect a view that positive and negative affect are redundant constructs because they are opposite poles along a single affective dimension (Russel and Carroll 1999). There is evidence, however, that positive and negative affect are minimally related (Cook et al. 2004a,b), are associated with different neural underpinnings (Cacioppo and Gardner 1999; Davidson 1992), and have different psychological correlates (Clark and Watson 1988; Watson et al. $1988 a, b)$.

Anhedonia is characterized by difficulties experiencing positive affect in response to typically rewarding situations (Loas 1996). Recognized as a prominent characteristic in major depressive episodes (Berenbaum and Oltmanns 1992), anhedonia is also conceptualized as a personality characteristic in the general population (Meehl 2001). Individuals at the upper end of the hedonic spectrum experience positive affect easily in response to natural rewards, whereas those at the lower end of the hedonic spectrum (anhedonia) experience more pronounced deficits in their ability to experience positive affect (Meehl 1975, 2001). Reduced ability to experience positive affect is theorized to be associated with attenuation of the mesolimbic dopamine system (Phillips 1984), one of the brain's reward centers. By self-administering nicotine, a dopamine releaser (Corrigall 1991; Gamberino and Gold 1999), anhedonic smokers may pharmacologically enhance their ability to experience positive mood states.

There is some evidence that acute nicotine administration has mild positive mood-enhancing effects among nondeprived smokers (Stein et al. 1998; Warburton and Mancuso 1998; Pomerleau and Pomerleau 1992; Argue 1973). However, it remains unknown whether nicotine enhances a smoker's ability to experience positive affect during exposure to typically pleasurable events. Indirect evidence for nicotine's ability to augment positive affective response to rewards may be abstracted from animal models. Nicotine administration enhances reward sensitivity to non-drug stimuli. Specifically, reward threshold, measured by the amount of electrical current rats self-administer intracranially (Kornetsky and Bain 1990), is lowered during nicotine administration (Huston-Lyons and Kornetsky 1992). Conversely, more intense electrical current is needed to trigger intracranial self-stimulation during nicotine deprivation (Epping-Jordan et al. 1988), signifying that reward function is diminished during nicotine abstinence. Thus, nicotine appears to enhance the rewarding properties of non-drug stimuli. Further, removal of nicotine appears to elevate brain reward set point such that non-drug rewards lack potency when not paired with an additional dopamine releaser.

Given that such conclusions have been derived from animal research, the role of the nicotine's effects on subjective positive mood remains unclear. The present study examined whether nicotine administration augmented anhedonic smokers' positive affective response during a positive mood induction. We hypothesized that anhedonia would moderate the effect of nicotine administration on positive affect during exposure to a positive mood induction such that nicotine's positive mood-enhancing effects would be stronger among smokers with higher levels of anhedonia.

\section{Materials and methods}

\section{Participants}

Participants $(n=50)$ were part of a larger experiment designed to test nicotine's influence on affect in smokers with and without a history of major depression. They were community members ranging from 18 to 65 years of age who smoked $\geq 15$ cigarettes per day for at least the past year. Recruitment strategies included advertisements in newspapers and on email list servers, as well as flyers posted around the community. Study candidates were excluded if they (1) were currently using nicotine replacement products, (2) met criteria for any current Axis I disorder other than nicotine dependence, (3) had been treated for alcohol or drug dependence (besides nicotine) within the past year, (4) were unable to read questionnaires, and (5) were perimenopausal. Participants were compensated $\$ 20.00$ for participation in the screening session and $\$ 40.00$ for each experimental session.

\section{Measures}

\section{Screening session measures}

Screening forms Questionnaires were used to characterize participants' demographic and smoking characteristics and to monitor enrollment biases.

Axis I disorders To assess current Axis I disorders and history of major depressive disorder, the Structured Clinical Interview for DSM-IV, non-patient version (SCID; Spitzer et al. 1992), was administered by a trained diagnostician. Diagnosticians were supervised by clinical psychologists to assess the reliability and accuracy of the assessments. The SCID (Spitzer et al. 1992) has moderate construct validity, as shown by its favorable comparison with other diagnostic assessment methods (Williams et al. 1992).

Anhedonia The Fawcett-Clark pleasure scale (FCPS) measured anhedonia by assessing how subjects responded to 36 pleasurable experiences (Fawcett et al. 1983). Using Likert 
scales, respondents rated how pleasurable they would find events like embracing a loved one or witnessing their grown child's success. Scores on the FCPS yield potential scores ranging between 36 and 180, with lower scores indicating higher levels of anhedonia (i.e., lower pleasure scores). Evidence for construct validity of the FCPS is shown by its correlation with the Chapman anhedonia scale $(r=-0.52$, $p<0.001$; Fawcett et al. 1983), a measure of anhedonia in schizophrenia (Chapman et al. 1976). Internal consistency for the current FCPS data was high: $\alpha=0.90$.

Nicotine dependence The Fagerstrom test for nicotine dependence (FTND; Heatherton et al. 1991) assessed level of nicotine dependence. Internal consistency for the FTND in the present study was low $(\alpha=0.58)$, but not substantially lower than what has been reported elsewhere $(\alpha=0.64$; Pomerleau et al. 1994).

Social desirability The Marlowe-Crowne social desirability scale (M-C SDS; Crowne and Marlowe 1960) measured the extent to which participants' responses to the positive mood induction might reflect their desire to give socially desirable answers. The scale's correlation with the Edwards social desirability scale $(r=0.35, p<0.01$; Crowne and Marlowe 1960) provides evidence of its construct validity. Internal consistency in the present sample was strong: $\alpha=0.85$.

Positive memory questionnaire During screening, a positive memory questionnaire was administered to obtain autobiographical memories for the positive mood inductions. Four positive memories were collected. For each memory, participants used a 1-to-10 scale to rate how happy the memory made them and how vivid it was. Comparably positive and vivid memories were selected for the two experimental conditions.

\section{Experimental and screening session measures}

Smoking status During screening and each experimental session, smoking status was evaluated via self-report and carbon monoxide (CO) ecolyzer test (EC-50, Vitalograph). Candidates whose $\mathrm{CO}$ measured $<8$ at screening were excluded from participation. Those whose screening CO indicated eligibility but whose $\mathrm{CO}$ was $<8$ at the beginning of an experimental session were rescheduled.

\section{Experimental session measures}

Positive and negative affect The positive affect-negative affect schedule (PANAS; Watson et al. 1988b) is a self-re- port affective state questionnaire that measures the subjective experience of positive and negative mood states. The ten-item positive affect subscale (Watson et al. 1988a,b) includes items such as enthusiastic, excited, and inspired. In the present sample, the positive affect subscale had high internal consistency: $\alpha$ ranged from 0.90 to 0.95 across assessment times. The ten-item negative affect PANAS subscale (Watson et al. 1988a,b) includes items such as distressed, hostile, and irritable. Strong internal consistency was observed in the present sample: $\alpha$ ranged from 0.84 to 0.91 across measurement times.

Nicotine withdrawal The Minnesota nicotine withdrawal scale (Hughes and Hatsukami 1986) was used to measure baseline symptoms of nicotine withdrawal. Acceptable internal consistency was observed in the present sample: $\alpha$ ranged from 0.78 to 0.83 .

Cigarette characteristic rating scale A cigarette characteristic rating scale measured cigarette taste and likeability (Pickworth et al. 1999) of the nicotinized and denicotinized cigarettes. Scale items, rated on 1-10 Likert scales, included such properties as "strength," "harshness," and "taste." Participants completed the cigarette taste rating scale during experimental sessions after smoking the experimental cigarettes.

\section{Procedure}

Screening Study candidates enrolled by telephoning the number listed on posted advertisements. They completed a brief telephone screening process during which the experimenter described the study and assessed the caller's interest in study participation. Candidates who met age and smoking status requirements were then scheduled for an inperson screening session. At the screening session, subjects received a full explanation of the study and provided written informed consent. The level of expired carbon monoxide (CO) was assessed with a carbon monoxide ecolyzer. Next, the experimenter administered the SCID diagnostic interview. Before the end of the screening session, subjects completed the FCPS, FTND, and questionnaires that assess smoking history. Finally, candidates completed a positive memory questionnaire. They recorded and rated four positive autobiographical memories, two were used as positive mood prompts.

Experimental sessions Experimental sessions involving nicotinized vs denicotinized cigarettes were administered in counterbalanced order. Female subjects were tested be- 
tween days 7 and 21 of the menstrual cycle to minimize influences of menstrual cycle hormonal fluctuations on affective response. All sessions were scheduled after $11 \mathrm{~A}$. M. and lasted approximately $1.5 \mathrm{~h}$. On testing days, participants were instructed to drink their normal amount of caffeine in the morning to avoid caffeine withdrawal effects. They were also asked to avoid caffeine $2 \mathrm{~h}$ before testing to prevent acute stimulating effects of caffeine on mood. Because sessions were scheduled after 11 A.M., participants were encouraged to smoke "as normal" before the trial. The two positive mood induction sessions were scheduled at the same time of day at least $24 \mathrm{~h}$ apart.

At the beginning of each experimental session, CO was assessed via ecolyzer. Participants were then asked to smoke one of their own cigarettes to ensure that they were not in withdrawal at the beginning of the session. Although the use of the smokers' own cigarette brand precluded controlling for absolute level of nicotine exposure, the procedure was adopted because it was considered more representative of each smokers' regular nicotine dose. After smoking their own cigarette, participants rested for $10 \mathrm{~min}$ in a comfortable chair to stabilize mood. After smoking and the rest period, baseline positive and negative affect were assessed via self-report mood measures. Participants also filled out the Minnesota nicotine withdrawal scale to monitor symptoms of nicotine withdrawal. Then they underwent a positive mood induction. The mood induction procedure involved two components: pleasant music and imagining a positive autobiographical memory. Participants were instructed to sit quietly for $7 \mathrm{~min}$ while listening to an audiotape of cheerful music. The positive music included excerpts from The Spring, The Summer, and The Fall of Vivaldi's Four Seasons. While listening to the music, they were prompted to remember a pleasant memory they reported during screening (instructions are available upon request to corresponding author). It has been established that listening to music and remembering a happy time in one's life invokes a positive mood state (Brewer and Doughtie 1980; Fiorito and Simons 1994) and produces stronger and more ecologically valid mood responses than generic scripts (Pitman et al. 1987). While listening and remembering, participants smoked a nicotinized or denicotinized cigarette during the full 7-min positive mood induction. Immediately after finishing the cigarette and mood induction, affect was re-assessed (T1). Then affect was again assessed after a 10-min rest (T2).

Nicotinized/denicotinized smoking conditions Nicotinized and denicotinized cigarettes were both produced by Lifetech and were matched on tar and carbon monoxide content. The nicotinized and denicotinized cigarettes had Federal Trade Commission-method-estimated nicotine de- liveries of 1.0 and $0.01 \mathrm{mg}$, respectively. They were presented in counterbalanced order, and their effects were contrasted so that pharmacological effects of nicotine could be examined while holding constant the sensory effects of smoking.

\section{Results}

Analytic plan

Random effects regression, implemented via SAS PROC MIXED, was used to measure the effect of nicotine administration on positive affect across time (condition-bytime interaction) and to test whether anhedonia moderated the influence of nicotine administration on positive affect (condition-by-time-by-anhedonia interaction). The variance-covariance matrix of the random effects regression was modeled using random subject intercepts with linear and quadratic trends. As recommended, this variance-covariance structure for the longitudinal data was selected as being most parsimonious only after comparison with several other potential structures (Verbeke and Molenberghs 2000). Both time and time squared were included in the model rather than orthogonal polynomials because they allowed for more meaningful interpretation of the regression estimates. Non-significant interaction terms were removed from the model in a backward manner (i.e., anhedonia by time squared first, then anhedonia by time) and the model was refit to determine the best-fitting model.

Preliminary analyses

Sample characteristics The sample consisted of 50 smokers. No data were missing from the primary independent or dependent variables. The mean age of the sample was 31.9 years $(\mathrm{SD}=11.3)$, and $50 \%$ were female. Thirty percent identified themselves as African-American, $8 \%$ as Asian-American, $56 \%$ as Caucasian, $4 \%$ as Latino-American, and $2 \%$ as multi-ethnic. Participants smoked an average of $19.6(\mathrm{SD}=5.3)$ cigarettes a day, had smoked for an average of 13.7 years $(\mathrm{SD}=10.9)$, and reported a mean score of $5.0(\mathrm{SD}=1.8)$ on the FTND (Heatherton et al. 1991).

Group differences in anhedonia Anhedonia was measured on a continuum for the primary analyses to preserve statistical power (Cohen 2005). However, simple effects analyses required that participants be divided via median split of the distribution of anhedonia scores $(\mathrm{Med}=137.5)$. Less anhedonic participants (referred to as the hedonic group; $n$ $=25$ ) included those who scored higher than 137.5 on the FCPS. More anhedonic participants (referred to as the an- 
Table 1 Demographic and smoking characteristics for anhedonic and hedonic smokers

\begin{tabular}{llll}
\hline Variable & Anhedonic smokers $(\boldsymbol{n}=\mathbf{2 5})$ & Hedonic smokers $(\boldsymbol{n}=\mathbf{2 5})$ & $\boldsymbol{P}$ value \\
\hline Age & $31.56(12.47)$ & $32.32(10.22)$ & 0.84 \\
Gender (female $=0$, male $=1)$ & $32 \%$ female & $68 \%$ female & $0.01 *$ \\
History MDD & $65 \%$ & $48 \%$ & 0.48 \\
FTND & $4.58(1.41)$ & $5.41(2.06)$ & 0.11 \\
Cigarettes/day & $19.88(6.11)$ & $19.24(5.46)$ & $13.30(9.49)$ \\
Years smoked & $14.04(12.30)$ & $53.08(4.71)$ & 0.67 \\
M-C SDS & $48.00(6.64)$ & $10.40(8.44)$ & 0.82 \\
Baseline withdrawal (denicotinized) & $11.40(9.86)$ & $12.80(8.96)$ & $0.003 * *$ \\
Baseline withdrawal (nicotinized) & $15.71(10.94)$ & $30.52(8.64)$ & 0.67 \\
Baseline positive affect (denicotinized condition) & $28.42(8.58)$ & $32.52(9.60)$ & 0.34 \\
Baseline positive affect (nicotinized condition) & $27.24(9.67)$ & 0.72 \\
\hline
\end{tabular}

$M D D=$ Major depressive disorder, $F T N D=$ Fagerstrom test for nicotine dependence, $M-C S D S$ = Marlowe-Crowne scale of social desirability

$* p<0.05$

$* * p<0.01$

hedonic group; $n=25$ ) scored less than 137.5 on the FCPS. Although clinical cut-offs for the FCPS have not been established, the average pleasure score within the anhedonic group $(M=125.27, \mathrm{SD}=12.82)$ is comparable to FCPS scores obtained in a clinically depressed sample $(M$ $=122.04, \mathrm{SD}=12.45$; Fawcett et al. 1983). Hedonics and anhedonics were compared on baseline smoking history and sociodemographic variables using one-way analyses of variance for continuously scaled variables and chi-squared tests for dichotomous variables (see Table 1). Only significant differences in social desirability and gender emerged, which were statistically controlled by placing these variables in the regression model as covariates.

Correlation analyses Pearson correlations between all study variables are shown in Table 2. Nicotine dependence was significantly correlated with the dependent variable, positive affect, and was therefore retained as a covariate.
Correlation analyses also examined the relationships between positive affect and negative affect across time (baseline, T1, T2) in both the nicotinized and denicotinized conditions. Correlation analysis showed that positive affect and negative affect were significantly negatively correlated across time (baseline, T1, T2; $r=-0.23$ to $-0.33, p<$ $0.05)$. Thus, as expected, positive affect was significantly, inversely correlated with negative affect, although not to the extent that they appeared to reflect opposite poles of the same construct.

Cigarette characteristic ratings Rated sensory characteristics of nicotinized vs denicotinized cigarettes were compared by related-samples $t$ tests. Results showed that participants rated the denicotinized compared to the nicotinized cigarettes as lower in satisfaction $(p=0.001)$, lower in good effects $(p=0.001)$, and higher in harshness $(p=$ $0.001)$. Correlation analyses examined whether ratings of

Table 2 Intercorrelations between study variables and positive affect in the nicotinized and denicotinized conditions

\begin{tabular}{|c|c|c|c|c|c|c|c|c|c|c|c|}
\hline & 1 & 2 & 3 & 4 & 5 & 6 & 7 & 8 & 9 & 10 & 11 \\
\hline 1. FCPS & - & & & & & & & & & & \\
\hline 2. FTND & 0.23 & - & & & & & & & & & \\
\hline 3. Age & 0.10 & $0.25^{*}$ & - & & & & & & & & \\
\hline 4. Gender & $-0.43 * * a$ & $-0.19^{\mathrm{a}}$ & $-0.07^{\mathrm{a}}$ & - & & & & & & & \\
\hline 5. M-C SDS & $0.34 * *$ & -0.11 & 0.18 & $-0.29 * a$ & - & & & & & & \\
\hline 6. PA Baseline-Denic & 0.20 & $0.34 *$ & 0.14 & $0.03^{\mathrm{a}}$ & 0.23 & - & & & & & \\
\hline 7. PA Time 1-Denic & 0.17 & $0.25^{*}$ & 0.17 & $0.01^{\mathrm{a}}$ & 0.17 & $0.86^{* *}$ & - & & & & \\
\hline 8. PA Time 2-Denic & $0.27 *$ & $0.37 * *$ & 0.20 & $0.05^{\mathrm{a}}$ & 0.18 & $0.89^{* *}$ & $0.80 * *$ & - & & & \\
\hline 9. PA Baseline-Nic & $0.35^{*}$ & $0.34 * *$ & 0.11 & $-0.04^{\mathrm{a}}$ & $0.24 *$ & $0.73 * *$ & $0.61 * *$ & $0.71 * *$ & - & & \\
\hline 10. PA Time 1-Nic & 0.17 & $0.26^{*}$ & 0.26 & $0.12^{\mathrm{a}}$ & 0.04 & $0.70^{* *}$ & $0.67 * *$ & $0.68^{* *}$ & $0.83 * *$ & - & \\
\hline 11. PA Time 2-Nic & 0.16 & $0.50^{* *}$ & 0.21 & $0.13^{\mathrm{a}}$ & 0.20 & $0.70 * *$ & $0.64 * *$ & $0.79 * *$ & $0.84 * *$ & $0.78 * *$ & - \\
\hline
\end{tabular}

FCPS = Fawcett-Clark pleasure scale, $M-C S C S=$ Marlowe-Crowne social desirability scale, $P A=$ positive affect

$* p<0.05$

$* * p<0.01$

aSpearman's rho 
Table 3 Predictors of positive affect from baseline to Time 2, determined by random effects regression modeling with unstructured covariance

\begin{tabular}{|c|c|c|c|c|}
\hline & Variable & Regression coefficient & Standard error & $t$ \\
\hline \multirow{4}{*}{ Covariates } & $\mathrm{Age}^{\mathrm{a}}$ & 0.21 & 0.10 & $2.22 *$ \\
\hline & Cigarette harshness ${ }^{\mathrm{b}}$ & 0.19 & 0.18 & 1.02 \\
\hline & Condition $(\text { Denic }=0, \mathrm{Nic}=1)^{\mathrm{b}}$ & -7.29 & 7.47 & -0.98 \\
\hline & Anhedonia $^{\mathrm{a}}$ & 0.22 & 0.08 & $2.90 * *$ \\
\hline \multirow[t]{5}{*}{ Interactions } & Anhedonia $\times$ Condition & 0.05 & 0.05 & 1.01 \\
\hline & Anhedonia $\times$ Time & -0.12 & 0.08 & -1.53 \\
\hline & Time $\times$ Condition & 13.56 & 5.78 & $2.34 *$ \\
\hline & Anhedonia $\times(\text { Time })^{2}$ & 0.07 & 0.04 & $2.00 *$ \\
\hline & Anhedonia $\times$ Time $\times$ Condition & -0.09 & 0.04 & $-2.15^{*}$ \\
\hline
\end{tabular}

${ }^{*} p<0.05$

$* * p<0.01$

${ }^{\text {a Time-invariant covariates }}$

bTime-varying covariates

harshness, satisfaction, and good effects were significantly associated with the outcome variable, positive affect. Only variables that were significantly associated with the outcome variables were entered into the final models (Keppel 1991). Analyses showed a significant relationship between harshness and positive affect at Time 2 in the nicotinized condition $(r=-0.24, p=0.03)$. Thus, in addition to social desirability, gender, and nicotine dependence, cigarette harshness was statistically controlled in all analyses. Condition order was not retained as a covariate because postinduction change in positive affect did not vary by condition order $[t(198)=0.34, p=0.78]$.

Primary analyses

Random effects regression tested the effects of anhedonia and nicotine condition on change in positive affect over time. The longitudinal analysis of positive affect yielded a significant condition-by-time interaction $[t(181)=2.21, p=$ 0.03 ], which was moderated by a significant three-way interaction between condition, time, and anhedonia $[t(181)=$ $-2.01, p=0.04]$. As hypothesized, the influence of nicotine on positive affect over time depended upon the level of anhedonia (see Table 3 ). ${ }^{1}$

Simple effects analyses were conducted among anhedonic participants and repeated among hedonic participants. For the anhedonic group, random effects regression analysis of the effects of nicotine on positive affect showed

\footnotetext{
1 The model was analyzed without covariates, and the three-way interaction remained significant. The same results emerged when history of depression, "cigarette satisfaction," and "cigarette good effects" were included as covariates in the model.
}

a significant condition-by-time interaction $[t(91)=2.47, p$ $=0.01$; see Table 4]. This was further interpreted by testing the simple effects of time for anhedonics in the nicotinized and the denicotinized conditions. Related-samples $t$ tests showed that anhedonic smokers experienced a significant increase in positive affect in response to positive mood induction when they were smoking a nicotinized cigarette $[t(24)=-3.59, p=0.001]$, but not when they were smoking a denicotinized cigarette $[t(24)=-0.68, p=0.50]$ (see Fig. 1). Furthermore, their mood declined significantly from post-mood induction (T1) to the delayed post-mood induction (T2) after smoking the denicotinized $[t(24)=$ $2.46, p=0.01]$, but not in the nicotinized cigarette $[t(24)$ $=1.88, p=0.07]$. When simple effects analyses were repeated for hedonic participants, the condition-by-time interaction was non-significant $[t(91)=0.34, p=0.73]$. In sum, therefore, the three-way interaction between anhedonia, nicotine condition, and time indicated that only anhedonic smokers showed a differential response to positive mood induction as a function of whether they were simultaneously smoking a nicotinized or a denicotinized cigarette.

For the sample as a whole, simple effects of time showed a significant decline in positive affect from post-mood induction (T1) to delayed post-mood induction (T2) during the denicotinized condition [t(49) $=2.81, p=0.007]$, but not during the nicotinized condition. Exploratory analyses indicated that both anhedonic and hedonic individuals showed differential post-induction mood change depending upon whether they self-administered nicotine during the induction. As Fig. 1 shows, both groups of smokers experienced a significant reduction in positive affect after smoking the denicotinized cigarette $[t(24)=2.46, p=0.02$ and 
Table 4 Simple effects analyses among anhedonic smokers examining predictors of positive affect from baseline to Time 2, determined by random effects regression modeling

\begin{tabular}{|c|c|c|c|c|}
\hline & Variable & Regression coefficient & Standard error & $t$ \\
\hline \multirow{3}{*}{ Covariates } & Social desirability ${ }^{\mathrm{a}}$ & 0.49 & 0.18 & $2.68 * *$ \\
\hline & Cigarette harshness ${ }^{\mathrm{b}}$ & 0.37 & 0.21 & 1.77 \\
\hline & Condition $(\text { Denic }=0, \mathrm{Nic}=2)^{\mathrm{b}}$ & -0.79 & 1.17 & -0.67 \\
\hline Time & $\begin{array}{l}\text { Time } \\
(\text { Time })^{2}\end{array}$ & $\begin{array}{l}4.20 \\
-2.78\end{array}$ & $\begin{array}{l}1.64 \\
0.76\end{array}$ & $\begin{array}{l}2.55^{*} \\
-3.65^{* *}\end{array}$ \\
\hline
\end{tabular}

$* p<0.05$

$* * p<0.01$

aTime-invariant covariates

${ }^{\mathrm{b}}$ Time-varying covariates

$t(24)=2.50, p=0.02$, respectively], but not after smoking the nicotinized cigarette.

\section{Ancillary analyses}

To the extent that positive affect is non-redundant with negative affect, it was expected that nicotine's influence on positive affect would remain significant after controlling for concurrently assessed negative affect. A significant condition-by-time interaction was present in the longitudinal analysis of positive affect $[t(180)=2.00, p=0.04]$ after controlling for nicotine dependence, social desirability, gender, cigarette harshness, and negative affect. Thus, the effect of nicotine administration on positive affect remained strong, even after removing the variance associated with negative affect. Next, random effects regression examined the influence of nicotine administration on negative affect, after controlling for positive affect. Random effects regression analyses showed a non-significant condition-bytime interaction $[t(181)=-0.54, p=0.67]$.

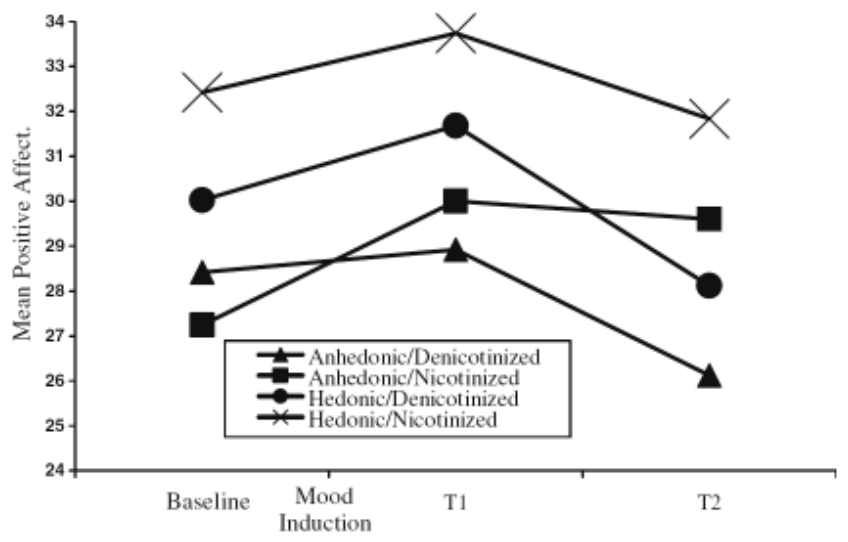

Figure 1 Mean positive affect over time [baseline, Time 1 (T1), Time 2 (T2)] while smoking nicotinized vs denicotinized cigarettes among anhedonic and hedonic smokers

\section{Discussion}

Although the pharmacologic effects of nicotine on mood are well established (Gilbert et al. 1998; Masson and Gilbert 1990; Perkins et al. 1992), there appears to be considerable individual variation in affective responsiveness to nicotine (Gilbert and Gilbert 1995). The present study demonstrated that individual differences in anhedonia moderated the magnitude of nicotine's effect on positive affect during a positive mood induction. As hypothesized, nicotine heightened the positive affect response among anhedonic participants but not among their higher hedonic counterparts. Self-administering nicotine enabled relatively anhedonic smokers to experience a significant increment in positive affect that was absent when they underwent a similar mood induction without nicotine. Individuals who have difficulties experiencing positive affect may learn to engage in compensatory behaviors, like smoking, that pharmacologically enhance their ability to experience positive mood states.

Although nicotine self-administration did not enhance more hedonic smokers' positive mood response, smoking a nicotinized cigarette buffered the rate at which positive affect dissipated after the mood induction. Similar effects of nicotine were found among anhedonic smokers. Consistent with our results, Conklin and Perkins (2005) found that smoking a cigarette (vs drinking water) maintained elevated positive affect during exposure to a positive mood induction. Regardless of the level of anhedonia, nicotine may enhance an individual's ability to sustain an already present positive mood state perhaps via the additional dopamine release triggered by smoking. If nicotine administration augments dopamine levels, smoking before a positive mood induction may also enhance affective responsiveness to the positive stimulus. Such findings might suggest that regular smoking increases positive emotional responding to environmental rewards, regardless of whether nicotine is 
simultaneously administered. Thus, altering the timing of nicotine administration with respect to the mood induction might provide relevant information about nicotine's positive mood effects.

Consistent with other evidence for the independence of positive and negative affect (Cook et al. 2004a,b; Cacioppo and Gardner 1999; Clark and Watson 1988; Watson et al. $1988 a, b$ ), our data indicate that nicotine's influence on positive affect was largely independent of changes in negative affect. Nicotine's selective influence on low positive affect may be especially clinically salient considering that anhedonia is an important feature of depression (Berenbaum and Oltmanns 1992), a psychiatric disorder that frequently co-occurs with smoking (Glassman et al. 1990). Although negative affect has been posited as a mechanism maintaining smoking in depression-prone smokers (Carmody 1992), deficient positive affect may be an additional pathway influencing comorbidity between nicotine dependence and depression. The present findings suggest a need to broaden existing theory about how nicotine's influence on positive mood contributes to the development and maintenance of smoking among smokers with comorbid depression.

The study had several limitations. To enhance the study's ecological validity, we chose to have participants smoke nicotinized and denicotinized cigarettes ad lib within a 7min period rather than using another form of nicotine administration. By having participants smoke experimental cigarettes, we relinquished control over the handling and dosing of the cigarettes. In addition, although the experimental cigarettes were designed to be matched on taste and sensory effects and are widely used for experimental research, differences were found. Although attempts were made to control for these differences statistically, differences in experimental cigarette likeability may have resulted in discrepant smoking rates across experimental sessions. In addition, the mean smoking rate in this sample was about 19 cigarettes per day, and it seems unlikely that many participants normally smoke twice within the chosen 20-min interval outside of the laboratory. Although the 20-min interval was chosen to produce a modest desire for a cigarette yet prevent onset of overt nicotine withdrawal symptoms, smoking within this timeframe may decrease the ecological validity of the study results. Further contributing to possible losses in ecological validity, ad-lib baseline smoking may have increased nicotine saturation before smoking the experimental cigarette.

Another limitation is that positive mood states brought on by real-world events may be different than positive mood states induced in a laboratory setting. Although autobiographical memories used in the present study were more ecologically valid than standardized positive slides or film clips, remembering a happy time in one's life may in- duce a different type of positive mood than the actual experience. In addition, vividness and pleasantness of the positive memory after the mood induction were not assessed. Although memories were matched on these ratings before testing, in the absence of a post-mood induction assessment, it is difficult to determine whether autobiographical memories were equally vivid and pleasant across sessions. Finally, the measure of positive affect used in the present study (PANAS) does not differentiate between separate dimensions of positive affect (activation vs valence; Lang 1994). Refinement of knowledge about nicotine's positive mood effects may include examination of whether smoking influences both activation and hedonic dimensions of positive affect.

In summary, the present results showed that nicotine disproportionately enhanced anhedonic smokers' positive mood response during a positive mood induction. Nicotine's enhancement of positive affect may help explain why anhedonic smokers exhibit strong cigarette craving after quitting smoking that is mediated by a loss in positive affect (Cook et al. 2004b). If anhedonic smokers miss and crave nicotine's positive mood-enhancing effects after quitting smoking, they may have a particularly difficult time maintaining abstinence. Research is needed to examine whether smokers with elevated anhedonia, such as currently depressed smokers, are at heightened risk for relapse via a deficient positive affect pathway. If borne out, findings would have implications for tailoring smoking cessation treatments. To the extent that positive mood enhancement proves to be a primary "hook" that binds anhedonic smokers to their cigarettes, successful quitting may require new pharmacologic options that target an under-responsive brain reward system.

\section{References}

Argue C (1973) Nicotine and smoking: effects upon subjective changes in mood. Psychopharmacologia 30:323-328

Berenbaum H, Oltmanns TF (1992) Emotional experience and expression in schizophrenia and depression. J Abnorm Psychology 101:37-44

Breslau N, Kilbey MM, Andreski P (1993) Nicotine dependence and major depression: new evidence from a prospective investigation. Arch Gen Psychiatry 50:31-35

Brewer D, Doughtie EB (1980) Induction of mood and mood shift. J Clin Psychol 36:215-226

Cacioppo JT, Gardner WL (1999) Emotions. Annu Rev Psychol 50:191-214

Carmody TP (1992) Affect regulation, nicotine addiction, and smoking cessation. J Psychoact Drugs 24(2):111-122

Chapman L, Chapman J, Raulin M (1976) Scales for physical and social anhedonia. J Abnorm Psychology 85:374-382

Clark LA, Watson D (1988) Mood and the mundane: relations be- 
tween daily life events and self-reported mood. J Pers Soc Psychol 54:296-308

Cohen J (2005) The cost of dichotomization. Appl Psychol Meas 7:249-253

Conklin CA, Perkins KA (2005) Subjective and reinforcing effects of smoking during negative mood induction. J Abnorm Psychology 114:153-164

Cook JW, Spring B, McChargue DE, Borrelli B, Hitsman B, Niaura R, Keuthen N, Kristeller J (2004a) The effect of fluoxetine on positive and negative affect during a clinic-based smoking cessation trial. Psychopharmacology 173:153-159

Cook JW, Spring B, McChargue DE (2004b) Hedonic capacity, cigarette craving and diminished positive mood. Nicotine Tob Res 6(1):39-47

Corrigall WA (1991) Understanding brain mechanisms in nicotine reinforcement. Br J Addict 86:507-510

Coyne JC (1994) Self-reported distress: analog or ersatz depression? Psychol Bull 116(1):29-45

Crowne DP, Marlowe D (1960) A new scale of social desirability independent of psychopathology. J Consult Psychol 24:349-354

Davidson RJ (1992) Anterior asymmetry and the nature of emotion. Brain Cogn 20:125-151

Epping-Jordan MP, Watkins SS, Koob GF, Markou A (1988) Dramatic decreases in brain reward function during nicotine withdrawal. Nature 393:76-79

Fawcett J, Clark DC, Scheftner WA, Gibbons RD (1983) Assessing anhedonia in psychiatric patients. Arch Gen Psychiatry 40:79-84

Fiorito ER, Simons RF (1994) Emotional imagery and physical anhedonia. Psychophysiology 31:513-521

Gamberino WC, Gold MS (1999) Neurobiology of tobacco smoking and other addictive disorders. Psychiatr Clin North Am 22:301-312

Gilbert DG, Gilbert BO (1995) Personality, psychopathology, and nicotine response as mediators of the genetics of smoking. Behav Genet 25:133-147

Gilbert DG, Jensen RA, Meliska CJ (1998) A system for administering quantified doses of tobacco smoke to human subjects: plasma nicotine and filter pad validation. Pharmacol Biochem Behav 31:905-908

Glassman AH, Helzer JE, Covey LS, Cottler LB, Stetner F, Tipp JE, Johnson J (1990) Smoking, smoking cessation, and major depression. J Am Med Assoc 264:1546-1549

Hall SM, Munoz F, Reus VI, Sees KL (1993) Nicotine, negative affect, and depression. J Consult Clin Psychol 61(5):761-767

Heatherton $\mathrm{T}$ et al (1991) The Fagerstrom test for nicotine dependence. Br J Addict 86:1119

Hughes JR, Hatsukami D (1986) Signs and symptoms of tobacco withdrawal. Arch Gen Psychiatry 43:289-295

Huston-Lyons D, Kornetsky C (1992) Effects of nicotine on the threshold for rewarding brain stimulation. Pharmacol Biochem Behav 41:755-759

Keppel G (1991) Design and analysis: a researcher's handbook. Prentice Hall, Englewood Cliffs, NJ

Kornetsky C, Bain G (1990) Brain-stimulation reward: a model for drug induced euphoria. In: Adler MW, Cowan A (eds) Modern methods in pharmacology testing and evaluation of drugs of abuse. Wiley, New York, pp 211-231
Lang PJ (1994) The motivational organization of emotion: affect-reflex connections. In: Van Goozen SHM, Van der Poll NE, Sergent JA (eds) Emotions: essays on emotion theory. Hillsdale, NJ: Erlbaum, pp 61-93

Loas G (1996) Vulnerability to depression: a model centered on anhedonia. J Affect Disord 41:39-53

Masson CL, Gilbert DG (1990) Cardiovascular responses to a quantified dose of nicotine as a function of personality and nicotine tolerance. J Behav Med 13:505-521

Meehl PE (1975) Hedonic capacity: some conjectures. Bull Menninger Clin 39(4):295-307

Meehl PE (2001) Primary and secondary hypohedonia. J Abnorm Psychology 110:188-193

Phillips AG (1984) Brain reward circuitry: a case for separate systems. Brain Res Bull 12:195-201

Pickworth WB, Fant RV, Nelson RA, Rohrer MS, Henningfield JE (1999) Pharmacodynamic effects of new de-nicotinized cigarettes. Nicotine Tob Res 1:357-364

Pitman RK, Orr SP, Forgue DF, De Jong JB, Claiborn JM (1987) Psycholphysiologic assessment of posttraumatic stress disorder. Arch Gen Psychiatry 44:970-975

Pomerleau C, Pomerleau OF (1992) Euphoriant effects of nicotine in smokers. Psychopharmacology 108:460-465

Pomerleau CS, Carton SM, Lutzke ML, Flessland KA (1994) Reliability of the Fagerstrom tolerance questionnaire and Fagerstrom test for nicotine dependence. Addict Behav 19:33-39

Perkins KA, Grobe JE, Fonte C, Beus M (1992) "Paradoxical” effects of smoking on subjective stress versus cardiovascular arousal in males and females. Pharmacol Biochem Behav 45:375-381

Russel JA, Carroll JM (1999) On the bipolarity of positive and negative affect. Psychol Bull 125:3-30

Spitzer RL, Williams JB, Gibbon M, Frist MB (1992) The structured clinical interview for DSM-III-R (SCID). History, rationale, and description. Arch Gen Psychiatry 49:624-629

Stein EA, Pankiewicz J, Harsch HH, Cho J, Fuller SA, Hoffmann RG, Hawkins M, Rao SM, Bendettini PA, Bloom AS (1998) Nicotine-induced limbic cortical activation in the human brain: a functional MRI study. Am J Psychiatr 155:1009-1015

Verbeke G, Molenberghs G (2000) Linear mixed models for longitudinal data. Springer, Berlin Heidelberg New York

Watson D, Tellegen A (1985) Toward a consensual structure of mood. Psychol Bull 98:219-235

Watson DA, Clark LA, Carey G (1988a) Positive and negative affectivity and their relation to anxiety and depressive disorders. J Abnorm Psychology 97:346-353

Watson D, Clark LA, Tellegen A (1988b) Development and validation of brief measures of positive and negative affect: the PANAS scales. J Pers Soc Psychol 54:1063-1070

Warburton DM, Mancuso G (1998) Evaluation of the information processing and mood effects of a transdermal nicotine patch. Psychopharmacology 135(3):305-310

Williams JBW, Gibbon M, First MB, Spitzer RL, Davies M, Borus J, Howes MJ, Kane J, Pope HG, Rounsaville B, Wittchen HU (1992) The structured clinical interview for DSM-III-R (SCID). Multisite test-retest reliability. Arch Gen Psychiatry 49:630-636 